\title{
Optical fibre temperature sensor in the cryogenic range
}

\author{
S. BERTRAND, A. JALOCHA, G. TRIBILLON, M. BOUAZAOUI, J. ROUHET
}

\begin{abstract}
The realization of an optical fibre sensor applied to cryogenic temperature measurement in harsh environments is presented. The measurement principle is based on the analysis of the decay-time of the fluorescence emitted by special doped crystals, the excited state lifetimes of which are greatly dependent on temperature. The sensor is intended to work in the presence of strong perturbations encountered on the testing benches of the liquid hydrogen and liquid oxygen turbo-pumps of the Ariane 5 Vulcan engine developed by 'la Societé Européenne de Propulsion (SEP)'. Copyright (C) 1996 Elsevier Science Ltd.
\end{abstract}

KEYWORDS: photoluminescence, fibre optic sensors, lasers, cryogenic temperatures, harsh environments

\section{Introduction}

Special needs for temperature control and regulation in harsh environments have given rise to the development of optical sensors resistant to such environments. Extrinsic sensors, where the optical fibre is used only as a transmission support, are well suited to severe surroundings, especially the fihre optic fluorescence techniques - most of which are collected and described by Grattan and Zhang'. One of the most prevalent methods is the analysis of the decay-time of the fluorescence emitted by doped crystals. This method leads to precise results with a good level of reproduction. The principle of the measurement with luminescent crystals is quite simple: under a photonic excitation pulse, the crystals emit a fluorescent signal with a temporal decrease greatly dependent on temperature. A lot of crystals are available to cover a large temperature range $e^{23}$.

In the cryogenic domain in which we are involved, calcium fluoride doped with divalent ytterbium $\left(\mathrm{CaF}_{2}: \mathrm{Yb}^{2+}\right)$ and strontium fluoride doped with divalent ytterbium $\left(\mathrm{SrF}_{2}: \mathrm{Yb}^{2+}\right)$ have a great sensitivity to temperature in the range $20 \mathrm{~K}-120 \mathrm{~K}$, which corresponds to liquid hydrogen and liquid oxygen temperatures. These two crystals constitute the sensitive part of the measurement probes, realized to withstand space norms such as thermal and mechanical strains (vibrations, high pressure, high speed flows) and have a good chemical compatibility with oxygen and

SB, AJ and GT are in the Laboratoire d'Optique PM Duffieux (URA CNRS no 214), Université de Franche-Comté, 25030 Besançon cedex, France. MB is in the Laboratoire de Spectroscopie Hertzienne (URA CNRS no 249), Université de Lille 1. 59655 Villeneuve d'Asca cedex. France. JR is with the Societé Européenne de Propulsion, Forèt de Vernon BP 802, 27207 Vernon cedex, France. AJ is presently in the Applied Optics Group, Department of Applied Physics, University of Twente, PO Box 217. 7500 AE Enschede, The Netherlands. Received 22 September 1994. Revised 15 June 1995. hydrogen ${ }^{4}$. The probes were tested on a liquid hydrogen turbo-pump at SEP. The tests showed a good resistance of the probes to thermal and mechanical strains as well as the good behaviour of the whole prototype sensor.

\section{Luminescent crystal properties}

The temperature measurement is based on the analysis of the fluorescence decay-time. Its strong dependence with respect to temperature is favourable for measurement precision. $\mathrm{CaF}_{2}: \mathrm{Yb}^{2+}$ and $\mathrm{SrF}_{2}: \mathrm{Yb}^{2+}$ crystals have a two-excited-states electronic structure. The lower state is metastable (that is, its transitions with the ground state are forbidden), and the upper state is the emitter state ${ }^{5,6}$. These two states are in thermal equilibrium within the temperature range $20 \mathrm{~K}-120 \mathrm{~K}$. Therefore, the time the electrons stay on the metastable state, in other words the fluorescent decay-time, varies greatly with the energy induced by thermal excitement in this cryogenic range $(20 \mathrm{~K}-120 \mathrm{~K})$. In a spectroscopic point of view, the absorption spectra at the low temperature of $\mathrm{CaF}_{2}: \mathrm{Yb}^{2+}$ and $\mathrm{SrF}_{2}: \mathrm{Yb}^{2+}$, show a high absorption band around $28500 \mathrm{~cm}^{-1}(\lambda \approx 350 \mathrm{~nm})$ (see Fig. 1) ${ }^{6,7}$. When they are excited in this ultraviolet absorption band, the crystals emit fiuorescent light centred on the yellow wavelength $(\lambda \approx 560 \mathrm{~nm})$ for $\mathrm{CaF}_{2}: \mathrm{Yb}^{2+}$ and the near-infrared $(\lambda \approx 800 \mathrm{~nm})$ for $\mathrm{SrF}_{2}: \mathrm{Yb}^{2+}$ (see Fig. 2) ${ }^{6}$.

\section{Basic principle of the measurement}

In response to a short duration ultraviolet excitation pulse, $\mathrm{CaF}_{2}: \mathrm{Yb}^{2+}$ and $\mathrm{SrF}_{2}: \mathrm{Yb}^{2+}$ crystals emit a fluorescent signal with a temporal decrease following the law

$$
I=A_{0} \mathrm{e}^{-1 / \tau_{i}}+B_{0} \mathrm{e}^{-1 / \tau_{s}}
$$

where $\tau_{\mathrm{f}}$ is a fast component of the excited state lifetime and $\tau_{\mathrm{s}}$ is a slow one. In the low temperature range, 


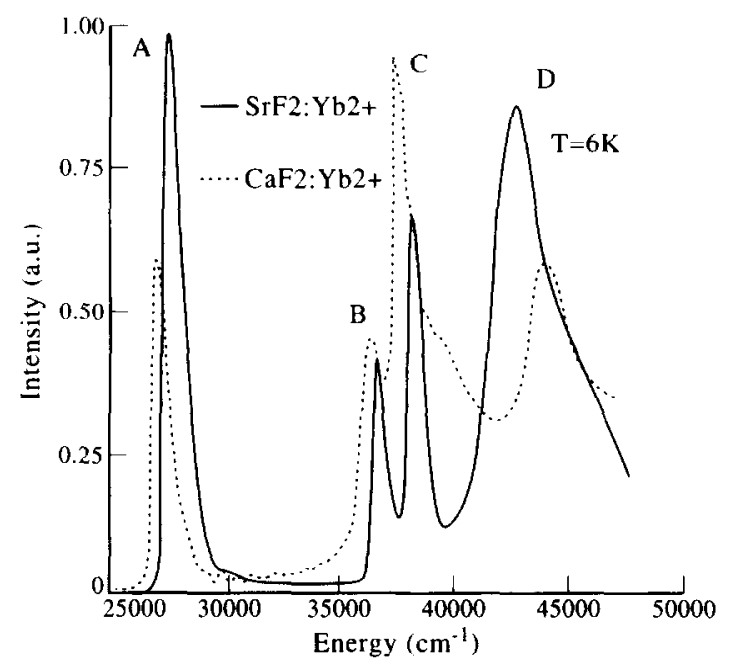

Fig. $1 \mathrm{CaF}_{2}: \mathrm{Yb}^{2+}$ and $\mathrm{SrF}_{2}: \mathrm{Yb}^{2+}$ absorption spectra at $T=6 \mathrm{~K}$

where radiationless processes are negligible, the lifetime is equal to $\tau_{\mathrm{s}}$. Moreover, $\tau_{\mathrm{f}}$ is too fast to be easily detected experimentally ${ }^{5,6}$. So we assume that the fluorescence signal decrease is given by the law

$$
I=I_{0} \mathrm{e}^{-t / \tau}
$$

where $I_{0}$ is the fluorescence intensity at the initial time and $\tau=\tau_{\mathrm{s}}$ is the excited state lifetime greatly dependent on temperature ${ }^{5,6}$. To calculate $\tau$, we apply a logarithmic regression to the fluorescent signal. We then obtain a straight line whose equation is $y=a x+b$, where the slope value, $a$, equals $-1 / \tau$ (see Figs 3 (a) and (b)). This calculation was applied to signals issued from $\mathrm{CaF}_{2}: \mathrm{Yb}^{2+}$ and $\mathrm{SrF}_{2}: \mathrm{Yb}^{2+}$ crystals, to define their working range:

(1) $\mathrm{SrF}_{2}: \mathrm{Yb}^{2+}$ crystal is better suited to low temperatures (from $20 \mathrm{~K}$ to $80 \mathrm{~K}$ ) with a decay-time varying from $10 \mu \mathrm{s}$ at $80 \mathrm{~K}$ to $120 \mu$ s at $20 \mathrm{~K}$;

(2) $\mathrm{CaF}_{2}: \mathrm{Yb}^{2+}$ crystal can cover the whole temperature range with a decay-time from $180 \mu \mathrm{s}$ at $120 \mathrm{~K}$ to $1100 \mu \mathrm{s}$ at $20 \mathrm{~K}$. However, its fluorescence efficiency is significantly higher between $80 \mathrm{~K}$ and $120 \mathrm{~K}$.

These two crystals are therefore perfectly complementary in the temperature range $20 \mathrm{~K}-120 \mathrm{~K}$. Between two consecutive excitation pulses, we have to wait for five times the decay-time value. Accordingly, temperature can be measured with a repetition rate ranging from $140 \mathrm{~Hz}$ to $20 \mathrm{kHz}$. It depends on the crystal used and the temperature range.

\section{Optical probe characteristics}

To measure temperature, we need two operations:

(i) luminescent crystal excitation by a short duration ultraviolet pulse;

(ii) fluorescent signal detection and processing.

The optical probe architecture is simple. It consists of a luminescent crystal, bonded at the extremity of a unique multimode optical fibre, guiding the ultraviolet beam towards the crystal and the fluorescence beam coming from the crystal. It is important to notice that the probes are conceived to be implemented on the cryogenic

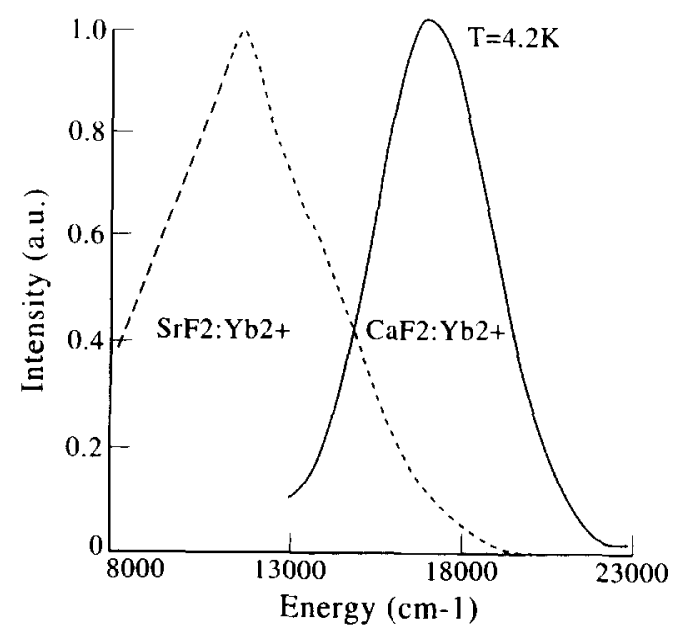

Fig. 2 Emission spectra at $T=4.2 \mathrm{~K}$ of $\mathrm{CaF}_{2}: \mathrm{Yb}^{2+}$ and $\mathrm{SrF}_{2}: \mathrm{Yb}^{21}$ crystals excited at $\lambda=355 \mathrm{~nm}$

turbo-pumps of the Vulcan engine, which introduce very strong perturbations such as:

- thermal strain: $20 \mathrm{~K}-120 \mathrm{~K}$;

- cryogenic fluids high pressure: $200 \mathrm{~atm}$;

- high speed flow of these fluids: from $100 \mathrm{~m} \mathrm{~s}^{-1}$ to $300 \mathrm{~m} \mathrm{~s}^{-1}$;

- mechanical vibrations;

- chemical compatibility of materials with hydrogen and oxygen.

It is therefore necessary to elaborate a mechanical system to protect the luminescent crystal affixed to the

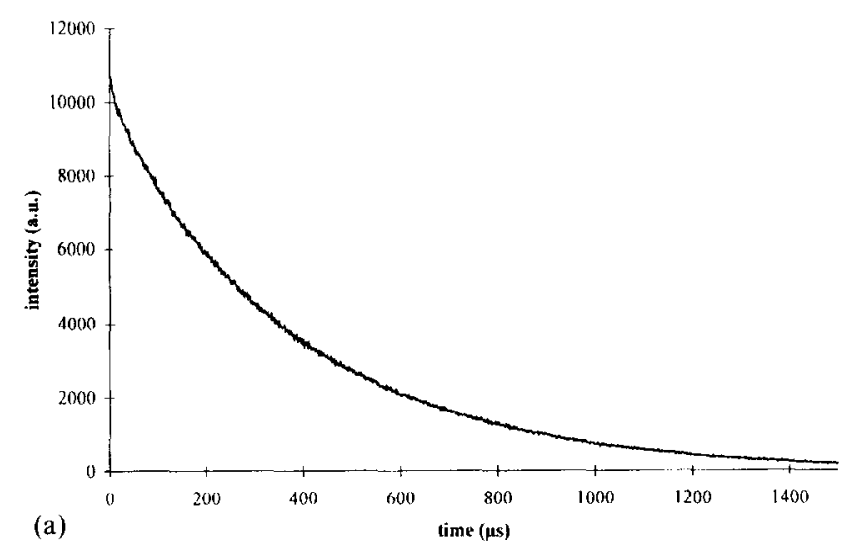

(a)

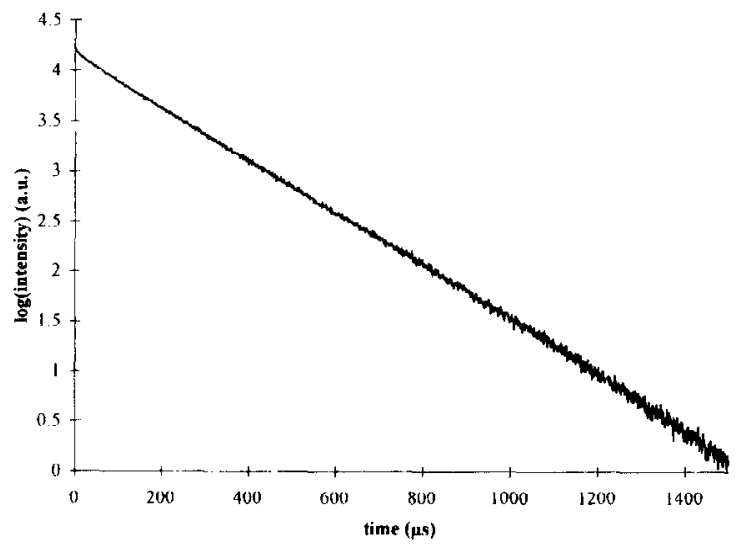

Fig. 3 (a) Fluorescent signal of $\mathrm{CaF}_{2}: \mathrm{Yb}^{2+}$ at $77 \mathrm{~K}$; (b) the same signal after logarithmic operation 


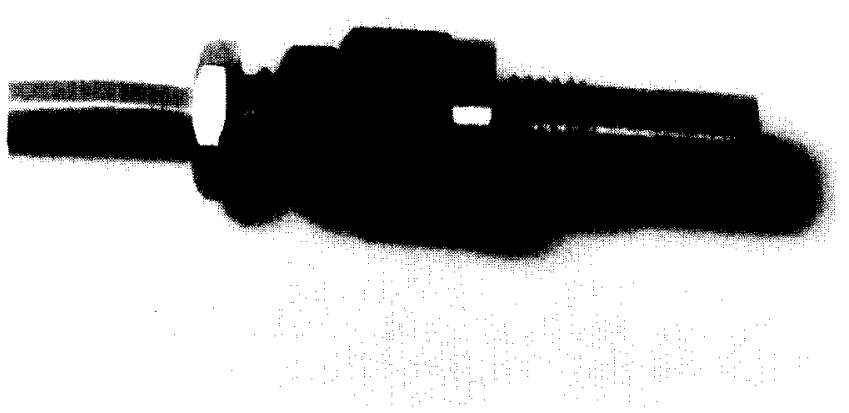

Fig. 4 Photograph of a probe

optical fibre with a special glue, having a low ultraviolet absorption coefficient and a good resistance to cryogenic and vibratory environments. To validate the choice of material and the probe concept, each of the strains previously listed was reproduced in specialized laboratories and applied to prototype probes. These laboratory tests led to the concept of a metallic capsule to protect the luminescent crystal as well as a mechanical interface for the implementation of the probes on the turbo-pumps (see Fig. 4).

\section{Experimental set-up and results}

The set-up scheme is presented in Fig. 5. The luminescent crystal is excited with a pulsed Nd: YLF frequency tripled laser $(\lambda=349 \mathrm{~nm})$ emitting $70 \mu \mathrm{J}$ energy pulses with 5 ns duration. The dichroic mirror is an essential component which divides excitation and fluorescence bcams. The fluorescence is detected by an avalanche photodiode. To achieve a good precision on the temperature measurement under the working conditions of the turbo-pumps, the analogue signal issued from the photodiode has to be sampled at $1 \mathrm{MHz}$ frequency and stored in a computer via a 14 bits acquisition board. The fluorescence decay-time value is calculated from this digitized signal and the corresponding temperature is then given by calibration curves stored beforehand.

For the calibration operation, the probes are placed in a liquid helium cryostat and the fluorescence decay-time is calculated for each temperature measured by a reference electric sensor located in the vicinity of the optical probes. The calibration curves are presented in Figs 6 and 7 . To determine temperatures from these curves, we develop a theoretical model from the experimental points. It is an $n$-order polynomial fitting, i.e.

$$
T=a_{0}+a_{1} \tau+\ldots+a_{n} \tau^{n-1}
$$

where $T$ is the temperature and $\tau$ the fluorescence decaytime. The performances of the sensor were estimated first in a static environment without any perturbations and then in actual working conditions of the turbopumps. In each case, temperature was calculated ten times per second to follow in quasi-real time the thermal evolution of the cryogenic fluids, especially when the turbo-pumps fircd. That repetition-rate is largely sufficient because the time-response of the probe is
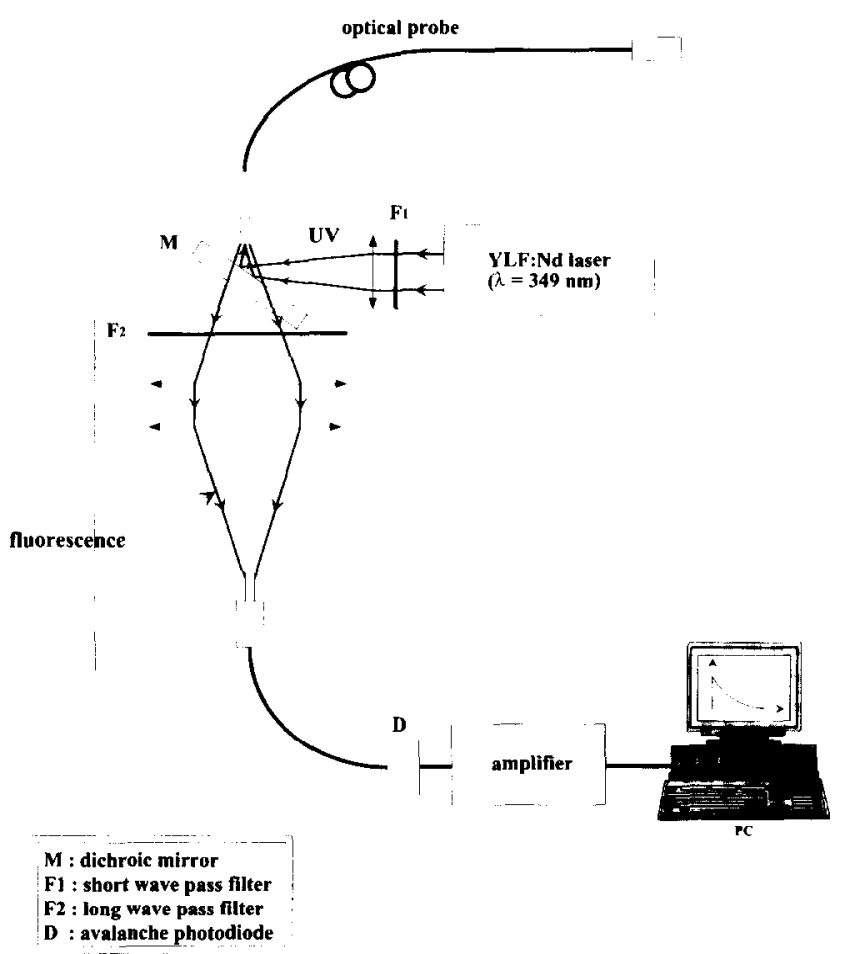

Fig. 5 Experimental set-up of the cryogenic temperature sensor by photoluminescence

actually estimated at $1 \mathrm{~s}$. The precision of the measurement given below, corresponds to the standard deviation around the mean value calculated from 50 signal acquisitions for a given temperature value. In the static environment, temperature was measured with a precision of $\pm 0.1 \mathrm{~K}$ in the best case $\left(\mathrm{SrF}_{2}: \mathrm{Yb}^{2+}\right.$ between $20 \mathrm{~K}$ and $60 \mathrm{~K}$ ), and $\pm 0.4 \mathrm{~K}$ in the worst one

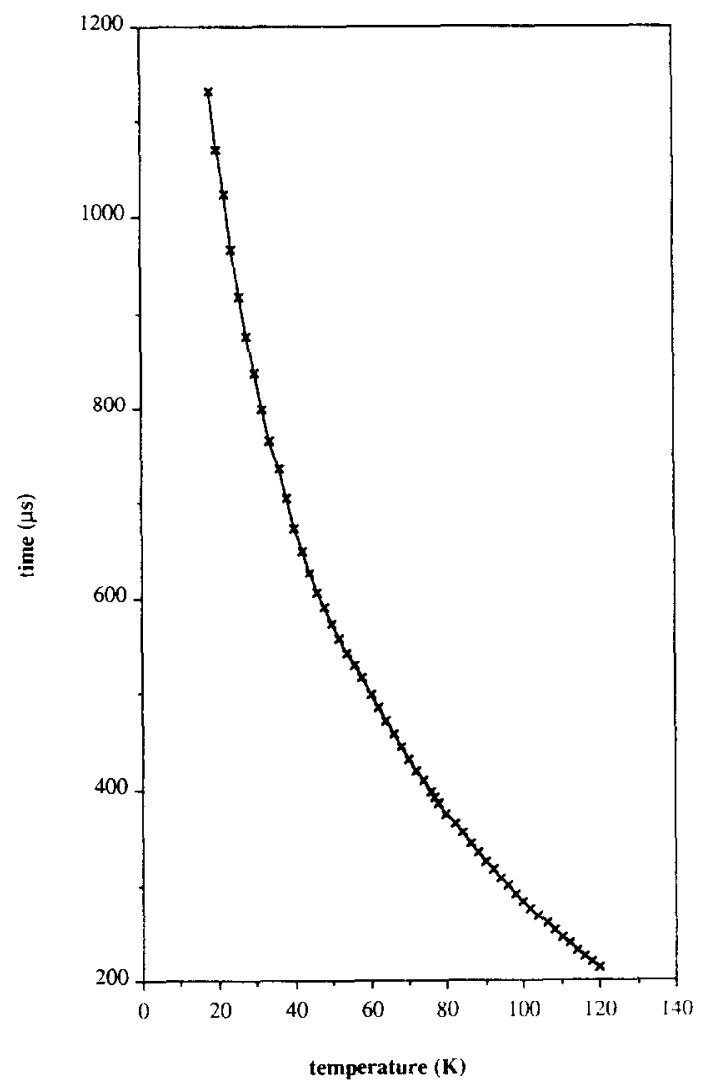

Fig. 6 Calibration curve of $\mathrm{CaF}_{2}: \mathrm{Yb}^{2+}$ 


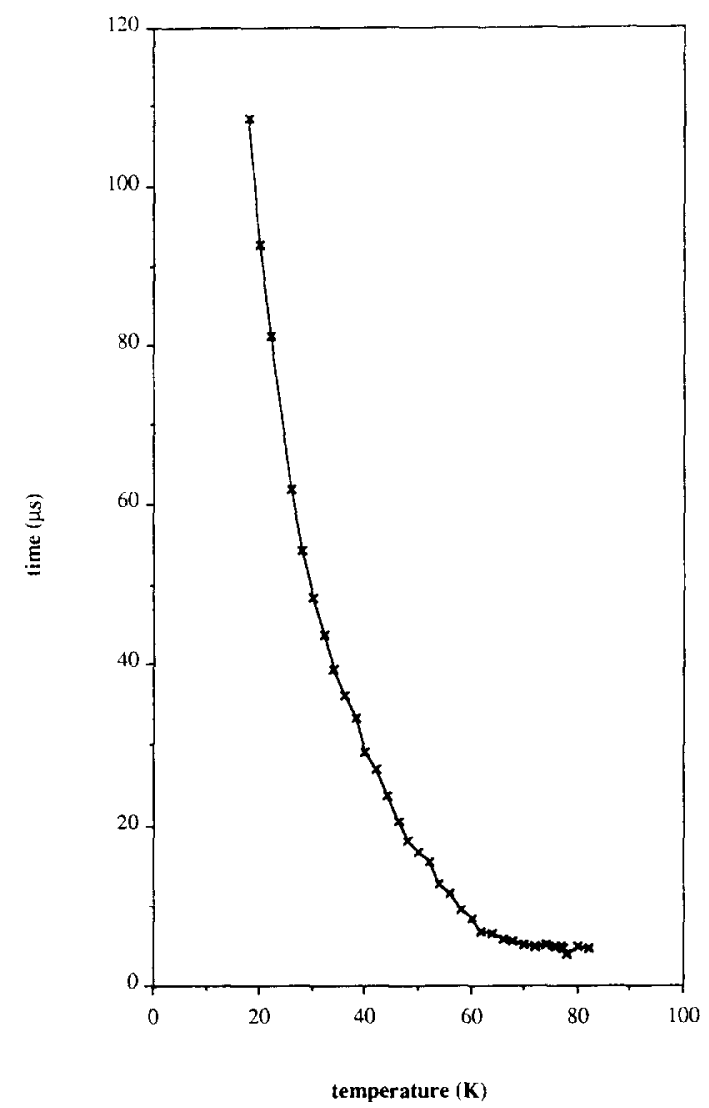

Fig. 7 Calibration curve of $\mathrm{SrF}_{2}: \mathrm{Yb}^{2+}$

$\left(\mathrm{CaF}_{2}: \mathrm{Yb}^{2+}\right.$ between $20 \mathrm{~K}$ and $\left.60 \mathrm{~K}\right)$. These first results are very satisfying and show that our sensor is among the most effective now available in the temperature range $20 \mathrm{~K}-120 \mathrm{~K}$.

To validate the optical sensor in the presence of drastic strains we implemented the two probes on a liquid hydrogen turbo-pump at 'la SEP'. This test illustrated the good behaviour of the optical probes versus thermal and mechanical strains as well as the good working of the whole sensor since temperature was measured with a precision equalling $\pm 0.3 \mathrm{~K}$ with $\mathrm{SrF}_{2}: \mathrm{Yb}^{2+}$ and $\pm 0.5 \mathrm{~K}$ with $\mathrm{CaF}_{2}: \mathrm{Yb}^{2+}$ when the turbo-pump fired.

\section{Conclusions}

We have shown that temperature measurement using the analysis of fluorescence decay-time allows the realization of optical sensors particularly resistant to harsh environments ${ }^{3,8}$. With a precision achieving $\pm 0.3 \mathrm{~K}$ in the presence of perturbations, this type of sensor is one of the most effective in the temperature range $20 \mathrm{~K}-120 \mathrm{~K}$. The possibility of performing measurements with a high repetition rate is a further advantage of this sensor which can detect transient thermal regimes ignored by conventional electric sensors. The insensitivity of optical probes to electromagnetic and chemical oxidizing surroundings, opens up this kind of sensor to numerous applications in many scientific domains, such as microelectronics, electrical engineering, biomedicine, etc ${ }^{l}$.

The major disadvantage of our sensor is its high cost and dimensions, but our aim was to demonstrate that the fluorescence decay-time analysis is a well-suited technique for the realization of optical temperature sensors in the cryogenic range working in very harsh environments. Nevertheless, we are working, at present. on an electronic circuit for hard calculation of the temperature, and we are studying the possibilities of developing a microchip ultraviolet laser to reduce the cost and dimensions of the sensor.

\section{Acknowledgement}

The work presented in this paper belongs to a technological and research program common to 'le Centre National d'Etudes Spatiales (CNES)' and 'la Société Européenne de Propulsion'.

\section{References}

1 Grattan, K.T.V., Zhang, Z.Y. Fiher Optic Fluorescence Thermometry, Chapman \& Hall (1995)

2 Noel, B.W., Borella, H.M., Francks, L.A., Marshall, B.R., Allison, S.W., Cates, M.R., Stange, W.A. Evaluating and testing thermographic phosphors for turbine engine temperature measurements, AIAA/SAE/ASME/ASEE 23rd Joint Propulsion Conference, San Diego (1987)

3 Luxtron Corp. Model 790 - a new generation of thermometry Santa Clara, USA (1993)

4 Rouhet, J., Tribillon, G., Bertrand, S., Boulon, G. Dispositif de mesure optique de température cryogénique, Patent n 9403797 . France (1994)

5 Courtois, B. Processus de photoionisation et mécanismes de fluorescence dions terres rares divalents $\mathrm{Eu}^{2+}$ et $\mathrm{Yb}^{2+}$ dans des monocristaux de fluorure alcalino-terreux $\mathrm{MF}_{2}(\mathrm{M}=\mathrm{Ca}, \mathrm{Sr}, \mathrm{Ba})$, Thesis, Lyon France (1990)

6 Moine, B., Courtois, B., Pedrini, C. I.uminescence and photoionisation processes of $\mathrm{Yb}^{2+}$ in $\mathrm{CaF}_{2}$ and $\mathrm{SrF}_{2}$ and $\mathrm{BaF}_{2}$, J Phys (France), 50 (1989) 2105

7 Loh, E. Ultraviolet absorption spectra of Europium and Ytterbium in alcaline earth fluorides, Phys Rev, 184 (1969) 348

8 Noel, B.W., Turley, W.D., Lewis, W., Tobin, K.W., Beshears, D.L. Phospor thermometry on turbine-engine blades and vanes, Temperature: Its Measurement and Control in Science and Industri, Vol. 6, Part 2, J.F. Schooley (Ed) (1992) 1249-1254 